\title{
Article \\ NiCo Nanoneedles on 3D Carbon Nanotubes/Carbon Foam Electrode as an Efficient Bi-Functional Catalyst for Electro-Oxidation of Water and Methanol
}

\author{
Tung Ngoc Pham 1,2,*, Ajaikumar Samikannu ${ }^{1}$, Solomon Tesfalidet ${ }^{1}{ }^{\mathbb{D}}$, Thomas Wågberg ${ }^{3}$ and \\ Jyri-Pekka Mikkola ${ }^{1,4, *}$
}

1 Chemical-Biological Centre, Technical Chemistry, Department of Chemistry, Umeå University, SE-90187 Umeå, Sweden; ajaikumar.samikannu@umu.se (A.S.); solomon.tesfalidet@umu.se (S.T.)

2 Faculty of Chemistry, The University of Danang-University of Science and Technology, 54 Nguyen Luong Bang, Lien Chieu, Da Nang 550000, Vietnam

3 Department of Physics, Umeå University, SE-90187 Umeå, Sweden; thomas.wagberg@umu.se

4 Process Chemistry Centre, Industrial Chemistry \& Reaction Engineering, Department of Chemical Engineering, Åbo Akademi University, FI-20500 Åbo-Turku, Finland

* Correspondence: pntung@dut.udn.vn (T.N.P.); jyri-pekka.mikkola@umu.se (J.-P.M.); Tel.: +84-90-567-0950 (T.N.P.); +46-(0)90-786-5284 (J.-P.M.)

Citation: Pham, T.N.; Samikannu, A.; Tesfalidet, S.; Wågberg, T.; Mikkola, J.-P. NiCo Nanoneedles on 3D Carbon Nanotubes/Carbon Foam Electrode as an Efficient Bi-Functional Catalyst for Electro-Oxidation of Water and Methanol. Catalysts 2021, 11, 500. https://doi.org/10.3390/catal11040500

Academic Editor: Yongjun Feng

Received: 18 March 2021

Accepted: 12 April 2021

Published: 15 April 2021

Publisher's Note: MDPI stays neutral with regard to jurisdictional claims in published maps and institutional affiliations.

Copyright: (c) 2021 by the authors. Licensee MDPI, Basel, Switzerland. This article is an open access article distributed under the terms and conditions of the Creative Commons Attribution (CC BY) license (https:// creativecommons.org/licenses/by/ $4.0 /)$.

\begin{abstract}
In this study, we report a 3D structured carbon foam electrode assembled from a bifunctional NiCo catalyst, carbon nanotubes (CNT), and a monolith 3D structured carbon foam (CF) as a highly active and stable electrode for oxygen evolution reaction (OER) and methanol oxidation reaction (MOR). When the NiCo@CNTs/CF electrode was used as an anode in OER, after the anodization step, the electrode required a small overpotential of $320 \mathrm{mV}$ to reach the current density of $10 \mathrm{~mA} \mathrm{~cm}^{-2}$ and demonstrated excellent stability over a long testing time (total $30 \mathrm{~h}$ ) in $1 \mathrm{M} \mathrm{KOH}$. The as-prepared NiCo@CNTs/CF electrode also exhibited a good performance towards methanol oxidation reaction (MOR) with high current density, $100 \mathrm{~mA} \mathrm{~cm}^{-2}$ at $0.6 \mathrm{~V}$ vs. $\mathrm{Ag} / \mathrm{AgCl}$, and good stability in $1 \mathrm{M} \mathrm{KOH}$ plus $0.5 \mathrm{M} \mathrm{CH}_{3} \mathrm{OH}$ electrolyte. The NiCo@CNTs/CF catalyst/electrode provides a potential for application as an anode in water electrolysis and direct methanol fuel cells.
\end{abstract}

Keywords: NiCo bi-functional catalyst; CNTs; carbon foam; OER; MOR

\section{Introduction}

In order to minimize the impact of non-renewable fossil fuels on the environment, the utilization of renewable electricity from renewable energy sources, such as solar and wind, is being rapidly expanded on a worldwide scale. Due to the supply-demand imbalance of electricity, sustainable storage, and conversion devices that convert electricity to another form of energy that later can be converted back to electricity are highly necessary [1]. Water electrolysis is one of the most attractive methods used to transform electrical energy to renewable hydrogen gas owing to the high purity of the produced hydrogen and, additionally, the environmentally friendly nature of the technology. In the water electrolysis process, under an applied potential, hydrogen is produced at cathode by hydrogen evolution reaction (HER), and oxygen gas is evolving at the anode through oxygen evolution reaction (OER) in which the sluggish kinetics of OER is the main cause leading to the higher energy consumption in the electrolysis system [2,3]. On the other hand, due to some major disadvantages of hydrogen fuel such as high cost, and complications in storage and transport, the cheaper and much safer methanol is investigated to be used as a fuel in a direct methanol fuel cell (DMFC), in which the methanol electro-oxidation reaction (MOR) at the anode is the most crucial. Unfortunately, similar to OER where noble metal-based catalysts such as $\mathrm{IrO}_{2}$ and $\mathrm{RuO}_{2}$ show their excellent electrocatalytic activities [2,4], precious metals such as $\mathrm{Pt}, \mathrm{Ru}$, and Pd are found to be very active for MOR [5-7]. These, 
however, display practical limitations owing to the high price and scarcity of these noble metals. Thus, electrocatalysts based on non-precious metals such as iron, nickel, and cobalt were studied as alternatives for noble metals [8-12].

In particular, earth-abundant catalysts such as metal oxides and hydroxides [13-17] and metal hybrids [18-25] have been widely studied as promising electrocatalysts for OER owing to their low price, high activity, and good stability. Among these earth-abundant electrocatalysts, $\mathrm{NiCo}$ based catalysts, such as $\mathrm{NiCo}_{2} \mathrm{O}_{4}$ and $\mathrm{NiCo}$ hydroxides, which can be easily synthesized through hydrothermal or electrodeposition methods [26-32] have attracted significant research interest as promising electrocatalysts for OER and also MOR. Besides, due to advantages, such as high electrical conductivity, large geometric surface area, and 3D open pore structure that facilitate the dispersion of electrolytes, as well as generated gases, nickel foam was selected as a substrate in many studies [26-29,31,33-37]. Despite its reputation, nickel foam has some major disadvantages, i.e., high cost and being a non-eco-friendly material due to the complex and high energy demanding manufacturing procedure $[38,39]$. Compared with nickel foam, carbon materials are considered as cheaper and more eco-friendly materials owing to the lower energy demand required for their production, as well as handling of the waste. Thus, carbon-based materials mainly comprising carbon fiber paper, carbon cloth, and glassy carbon were used as an electrode substrate $[8,32,40-43]$ in some studies but still at a much lesser extent compared with that of nickel foam.

In this study, we developed a 3D structured carbon-based electrode NiCo@CNTs/CF in which the carbon nanotubes and carbon foam were completely covered by the nanoneedles of NiCo catalyst which can be used as a bi-functional catalyst for OER and MOR. The smart design electrode has many advantages originating from the property of each component such as the good electrocatalytic activity of the NiCo catalyst, high electrical conductivity, and high chemical resistance of CNTs, further coupled to the 3D open-pore cell structured of the carbon foam [44]. For OER, boosted by anodization process, the electrode requires a small overpotential of only $320 \mathrm{mV}$ to reach the current density of $10 \mathrm{~mA} \mathrm{~cm}^{-2}$. Furthermore, the developed electrode showed excellent stability in a series of galvanostatic tests ( $30 \mathrm{~h}$ in total), at a constant current density of $10 \mathrm{~mA} \mathrm{~cm}^{-2}$ in $1 \mathrm{M}$ of $\mathrm{KOH}$ electrolyte. For MOR, the NiCo@CNTs/CF also exhibits remarkable performance where the electrode shows high electrocatalytic activity in which a high current density of $100 \mathrm{~mA} \mathrm{~cm}{ }^{-2}$ was achieved at $0.6 \mathrm{~V}$ vs. $\mathrm{Ag} / \mathrm{AgCl}$ in $1 \mathrm{M} \mathrm{KOH}$ with $0.5 \mathrm{M}$ methanol. Moreover, the prepared electrode also shows outstanding stability with no decay observed in the current density during potentiostatic tests at the constant potential of $0.4 \mathrm{~V}$ vs. $\mathrm{Ag} / \mathrm{AgCl}$. This raises the potential of the electrode to be used as an efficient, low-cost, and eco-friendly anode for OER in a water splitting system as well as MOR in a direct methanol fuel cell.

\section{Results and Discussion}

\subsection{Material Characterizations}

The morphology of synthesized carbon nanotubes (CNT) on carbon foam (CF) and NiCo catalyst on the CNTs / CF were revealed using the SEM technique. Figure 1a shows the 3D open-pore structure of carbon foam with the curved carbon nanotubes on the carbon frame which remained after the pyrolysis and catalytic chemical vapor deposition (CCVD) processes. After the catalyst decoration step, the surface of the sample (NiCo@CNTs/CF) was completely covered by needle-like nanostructures that have a length of more than $200 \mathrm{~nm}$ (Figure 1b) which is expected to have a big impact on the surface area of the material. To address this issue, the B.E.T. surface area of CNTs/CF and NiCo@CNTs/CF samples was calculated based on nitrogen sorption and desorption analysis of the corresponding samples (Figure S1). The results showed that the NiCo@CNTs/CF has a higher specific surface area $\left(\sim 110 \mathrm{~m}^{2} \mathrm{~g}^{-1}\right)$ than the support surface $\left(\mathrm{CNTs} / \mathrm{CF}, \sim 87 \mathrm{~m}^{2} \mathrm{~g}^{-1}\right)$, due to the presence of NiCo nanostructures. The distribution of $\mathrm{Ni}$ and $\mathrm{Co}$ elements on the surface of NiCo@CNTs/CF was investigated using the energy-dispersive X-ray spectroscopy 
(EDS) mapping analysis. To investigate the distribution of $\mathrm{Ni}$ and Co elements, the energy dispersive X-ray spectroscopy (EDS) mapping analysis of NiCo@CNTs/CF sample was performed. The acquired images (Figure 1c-f), in which carbon, nickel, and cobalt were indexed in yellow, blue, and purple colors, respectively, illustrate a homogeneous distribution of $\mathrm{Ni}$ and $\mathrm{Co}$ throughout the carbon frame. The catalyst loading of the sample, determined using thermal gravimetric analysis (TGA) measurement on NiCo@CNTs/CF and CNTs/CF, was found to be ca $22.5 \mathrm{wt}$.\% (Figure S2). This was further supported by inductively coupled plasma optical emission spectroscopy (ICP-OES), where the measurement of $\mathrm{Ni}$ and $\mathrm{Co}$ in digested $\mathrm{NiCo} @ \mathrm{CNTs} / \mathrm{CF}$, estimating the atomic ratio of $\mathrm{Ni}-\mathrm{Co}$ to be $1.3-1$, resulted in a catalyst loading of $\sim 21.7 \mathrm{wt} . \%$.
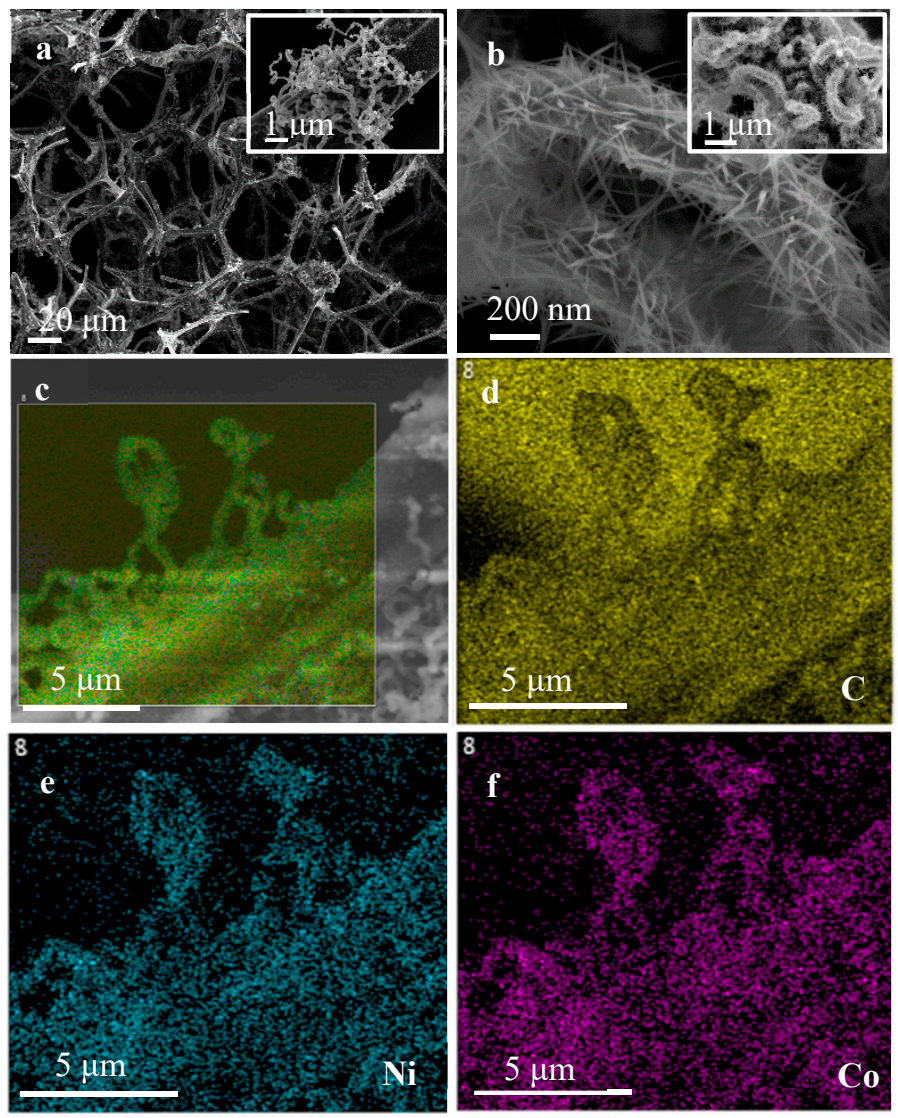

Figure 1. SEM images of (a) the blank CNTs/CF and (b) pristine NiCo@CNTs/CF samples. (c-f) SEMEDX elemental mapping of NiCo@CNTs/CF sample for C, Ni, and Co elements.

The crystalline phase of the as-made NiCo@CNTs/CF, and also the blank (CNTs/CF) samples were studied by the X-ray diffraction (XRD) technique. As shown in Figure 2a, the XRD pattern of CNTs/CF sample exposes the presence of CNTs by peaks at the $2 \theta$ of $27.8^{\circ}$, and $44^{\circ}$ and also $\mathrm{Co}^{\circ}$, using as a catalyst for CNTs, through peaks at the $2 \theta$ of $44.6^{\circ}$, and $51^{\circ}$ [45]. On the other hand, the XRD pattern of the pristine NiCo@CNTs/CF displays several new peaks at $2 \theta$ of $\sim 37^{\circ}, 44^{\circ}$, and $63.0^{\circ}$ which, based on the value in the standard card of JCPDS card \# 48-1719 (CoO) and 04-0835 (NiO), can be characterized as $\mathrm{CoO}$, and $\mathrm{NiO}$. The chemical composition and oxidation states of $\mathrm{Ni}$ and $\mathrm{Co}$ in the fresh $\mathrm{NiCo@CNTs/CF} \mathrm{sample} \mathrm{were} \mathrm{determined} \mathrm{using} \mathrm{XPS} \mathrm{analysis.} \mathrm{The} \mathrm{XPS} \mathrm{wide} \mathrm{spectrum}$ of the sample confirms the presence of $\mathrm{Ni}, \mathrm{Co}, \mathrm{C}, \mathrm{N}$, and $\mathrm{O}$ in the sample (Figure S3). As can be seen from Figure $2 b$, the deconvoluted spectrum of Ni $2 p_{3 / 2}$ shows the presence of 3 nickel components that can be assigned as metallic $(852.8 \mathrm{eV})$, oxide $(854.1 \mathrm{eV})$, and hydroxide $(855.7 \mathrm{eV})$ [46]. The oxidation stage of cobalt in the sample was also identified through the Co $2 p$ high-resolution spectrum (Figure 2c) where the two main peaks at $780 \mathrm{eV}$ 
(Co 2p $\mathrm{p}_{3 / 2}$ ) and $796 \mathrm{eV}\left(\mathrm{Co} 2 \mathrm{p}_{1 / 2}\right)$ entailed that the major amount of cobalt in the sample surface is in the oxide form $[46,47]$. The oxidation state of nickel and cobalt are further confirmed by $\mathrm{O} 1 \mathrm{~s}$ spectra (Figure 2d): the two main peaks at 529.7 and $531.5 \mathrm{eV}$ can be assigned to metal-bound oxygen $(\mathrm{M}=\mathrm{O})$ and metal-bound hydroxide $(\mathrm{M}-\mathrm{OH})$ group [46], respectively, in which the first peak is the dominating peak. Thus, based on XRD and XPS results, we can conclude that our as prepared catalyst contains three phases in which the phase of metal oxides is dominant.
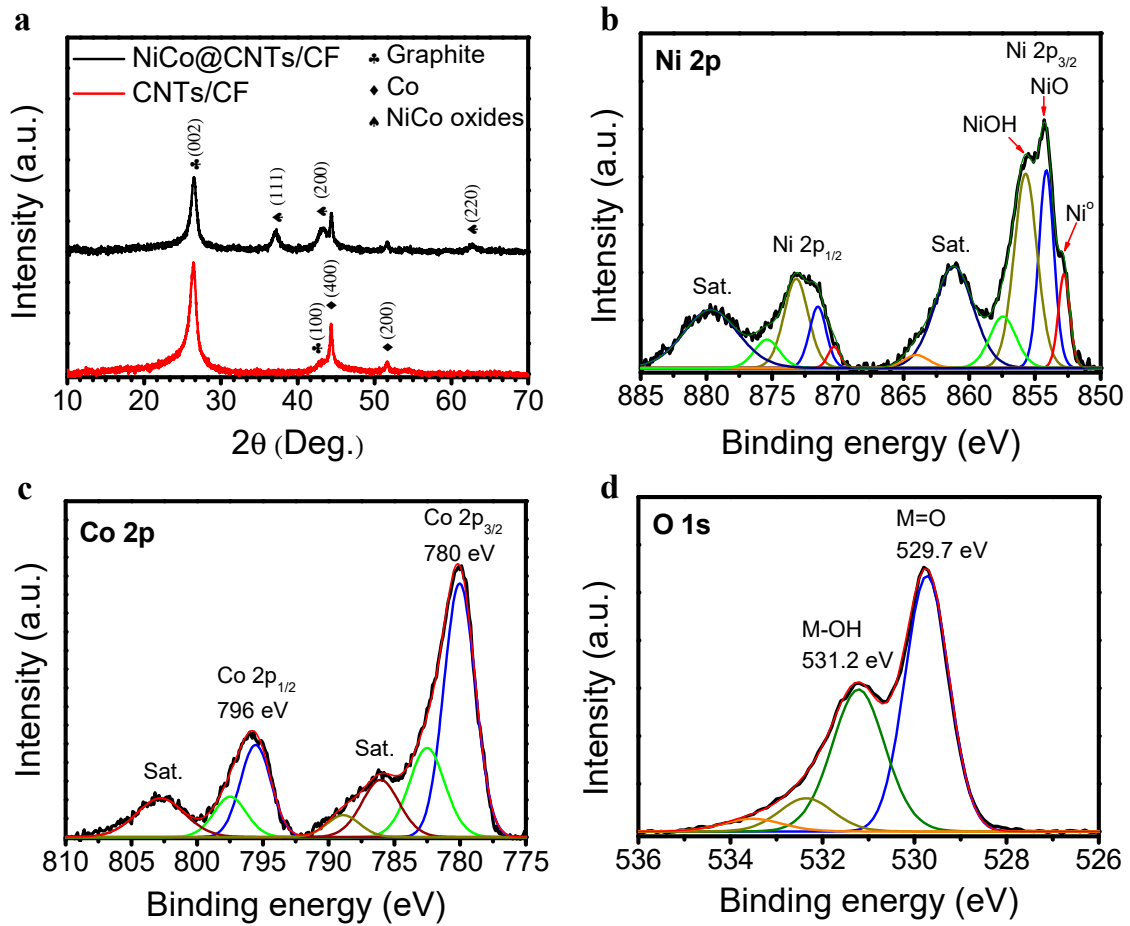

Figure 2. (a) XRD patterns of the pristine NiCo@CNTs/CF and blank (CNTs/CF) sample. XPS high resolution spectra of (b) Ni 2p, (c) Co 2p, and (d) O 1s of the pristine NiCo@CNTs/CF.

\subsection{The OER Performance}

The OER activity of the NiCo@CNTs/CF, before and after the anodization, was investigated by polarization scans at $5 \mathrm{mV} \mathrm{s}^{-1}$ in $1 \mathrm{M} \mathrm{KOH}$. As shown in Figure 3a, the pristine electrode, named as $\mathrm{NiCo}-\mathrm{Sp} 0$, exhibits a quite low electrocatalytic activity which needs an overpotential of approximately 400 and $660 \mathrm{mV}$ to reach the current density of 10 and $100 \mathrm{~mA} \mathrm{~cm}^{-2}$, respectively. To improve the performance towards OER of the electrode, an anodization step was included at a constant current density of $10 \mathrm{~mA} \mathrm{~cm}{ }^{-2}$ in $10 \mathrm{~h}$ in $1 \mathrm{M} \mathrm{KOH}$ which also can be considered as the 1st galvanostatic cycle (Figure $3 \mathrm{~b}$ ). After the anodization step, the electrode, entitled NiCo-Sp1, shows a huge enhancement of the electrocatalytic activity in which the overpotential (n) that corresponds to the current density of $10 \mathrm{~mA} \mathrm{~cm}^{-2}$ dropped to below $320 \mathrm{mV}$, which is comparable with other reported NiCo based catalysts but still higher than that of the benchmark catalysts, e.g., NiFe based catalysts (Table S1). Moreover, the Tafel plots (Figure 3c) obtained from the polarization curves show a similar result where the calculated Tafel slope of the NiCo-Sp1 $\left(82 \mathrm{mV} \mathrm{dec}^{-1}\right)$ is much smaller than that of the $\mathrm{NiCo}-\mathrm{Sp} 0\left(127 \mathrm{mV} \mathrm{dec}^{-1}\right)$, indicating improved catalytic kinetics of the catalyst after the anodization step. It is worth mentioning that the estimated Tafel slope value of the NiCo@CNTs/CF (NiCo-SP1) is similar to the reported values of NiCo based catalysts which also is in agreement with the overpotential values (Table S1). To explain the enhancement, electrochemical impedance spectroscopy (EIS) experiment was conducted before and after the anodization step at the overpotential of $0.3 \mathrm{~V}$. Remarkably, the Nyquist plots of the pristine and anodized electrodes (Figure 3d) show two semicircles which is not often seen in common OER electro-catalyst systems [48]. The achieved 
Nyquist plots can be explained using a model (Figure S4) in which the semicircle at the high frequency region is linked to the resistivity of the topmost oxide layer which the current has to pass through before reaching underlying layers of the catalyst/electrode, the charge transfer resistance $\left(\mathrm{R}_{\mathrm{ct}}\right.$ in the model). The second semicircle found at the low frequency domain is associated with the underlying compact oxide layer [49] in which $R_{1}$ is the resistivity of the layer. Using the model, the $\mathrm{R}_{\mathrm{ct}}$ value of the NiCo-Sp1 Nyquist plot was estimated to be $\sim 20 \Omega$ which is much smaller than that of the fresh catalyst, NiCo-Sp0 $(\sim 97 \Omega)$. As shown in the corresponding Bode-phase diagrams (Figure 3d (inset)), the two peaks at low (from $10^{-1}$ to $10^{1} \mathrm{~Hz}$ ) and medium-high (from $10^{3}$ to $10^{5} \mathrm{~Hz}$ ) region are in agreement with the two semicircles observed in Nyquist plots. Interestingly, after the anodization process, the peaks were found to be shifted towards the low frequency region which implied a dramatic change in the characteristics of the NiCo catalyst. The result indicates that after the anodization, the NiCo catalyst possesses a lower charge transfer resistance and also faster kinetics in OER than the fresh catalyst. Furthermore, the double layer capacitance $\left(\mathrm{C}_{\mathrm{dl}}\right)$ of the electrode before and after the anodization which is directly proportional to the electrochemically active surface area (ECSA), was estimated using cyclic voltammograms (CV) in a non-Faradaic potential region (Figure S5). After the anodization, the $\mathrm{C}_{\mathrm{dl}}$ value of NiCo@CNTs/CF was calculated to be $24.5 \mathrm{mF} \mathrm{cm}^{-2}$ which is approximately double the $\mathrm{C}_{\mathrm{dl}}$ value of the pristine electrode $\left(13.1 \mathrm{mF} \mathrm{cm}^{-2}\right)$. The higher value of $\mathrm{C}_{\mathrm{dl}}$ indicates that after the anodization, the electrode has more active sites for the water oxidation reaction leading to the observed increase in the OER performance of the electrode.

a

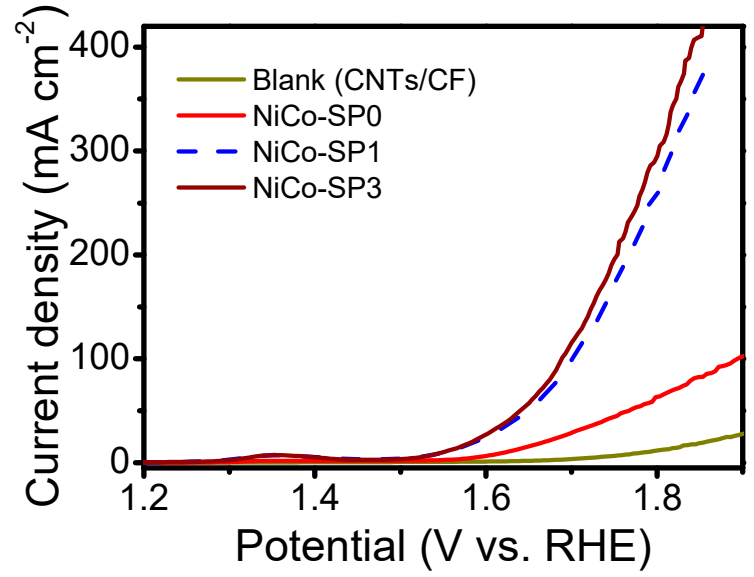

c

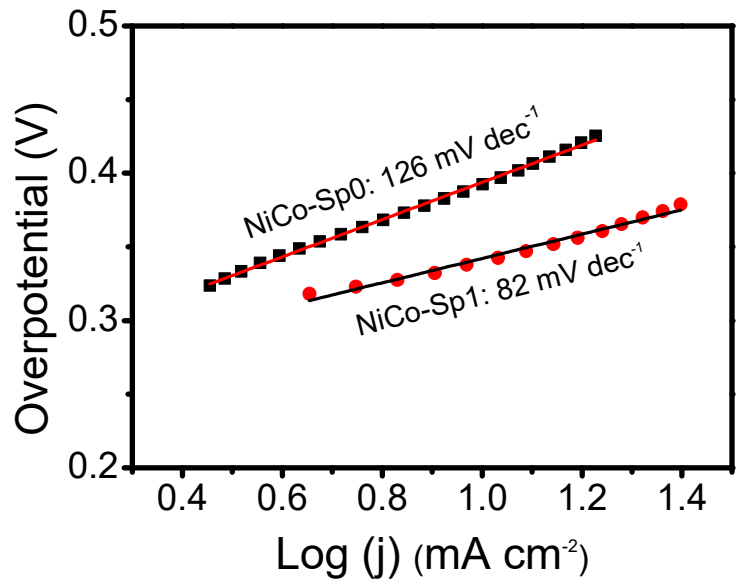

b

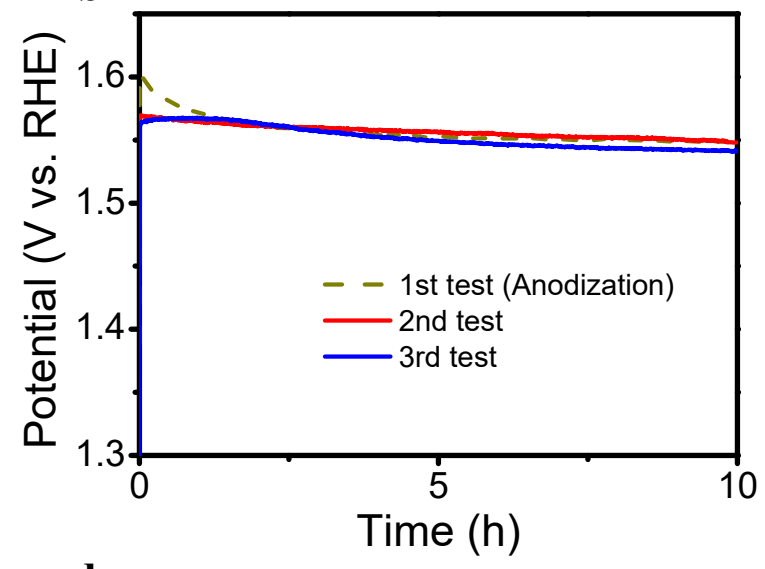

d

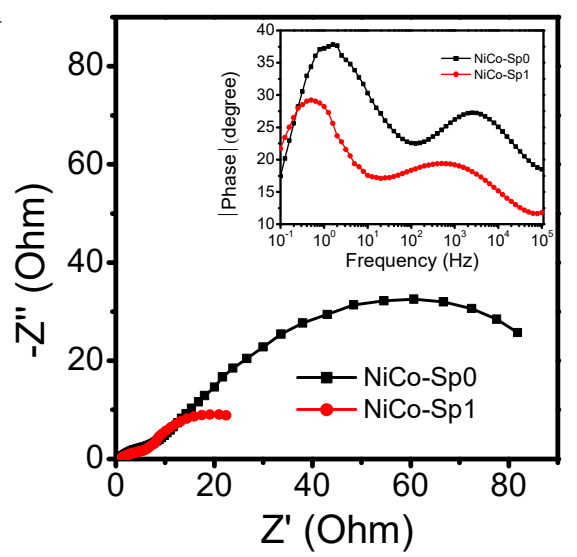

Figure 3. (a) Polarization curves of the blank (CNTs/CF) and NiCo@CNTs/CF electrodes before and after each stability tests, (b) Chronopotentiometry curves including anodization step of the NiCo@CNTs/CF electrode at constant current density of $10 \mathrm{~mA} \mathrm{~cm}^{-2}$. (c) The Tafel slope and (d) the Nyquist plots and corresponding Bode-phase plots (inset) of the NiCo@CNTs/CF electrode before and after the anodization at the overpotential of $0.3 \mathrm{~V}$. 
To investigate the stability of the NiCo@CNTs/CF after the anodization step, two consecutive cycles of the galvanostatic test were performed in which each cycle has the testing time of $10 \mathrm{~h}$, at a constant current density of $10 \mathrm{~mA} \mathrm{~cm}^{-2}$. As shown in Figure $3 \mathrm{~b}$, during the 2nd as well as the 3rd test, the NiCo@CNTs/CF electrode exhibits excellent durability which shows no decrease but a slightly better electrocatalytic activity at the end of each test. The observed trend was further confirmed by the Linear Sweep Voltammetry (LSV) taken after the third test (NiCo-Sp3) which shows a slightly better OER performance than that of the NiCo-Sp1 (Figure 3a). To further study the durability of the electrode, possible leaching of $\mathrm{Ni}$ and $\mathrm{Co}$ into the electrolyte during the stability tests was checked using ICP-OES. The ICP-OES results showed no sign of the presence of $\mathrm{Ni}$ in the electrolyte, which probably is under the detection limit of the instrument, and only a small amount of Co $(\sim 0.4 \mathrm{ppm})$ after three consecutive galvanostatic tests $(30 \mathrm{~h}$ in total at a constant current density of $10 \mathrm{~mA} \mathrm{~cm}^{-2}$ ). It is worth noting that, the amount of the leached cobalt is very small $(\sim 2.8 \mu \mathrm{g})$, which is only $0.2 \%$ of the total amount of the cobalt catalyst.

The morphology, as well as the chemical composition and oxidation stage of the catalyst, after the third galvanostatic test, NiCo-Sp3, were also studied by SEM and XPS techniques. The SEM images of the NiCo-Sp3 (Figure S6) reveals that the morphology of the NiCo catalyst, with needle-like structures on the surface of the $\mathrm{CNTs} / \mathrm{CF}$, has remained after the stability tests. The result from SEM-EDX elemental mapping of the NiCo-Sp3 sample has also proven for the homogeneous distribution of $\mathrm{Ni}$ and Co catalyst after the third galvanostatic test (Figure S7). The wide spectrum of the NiCo-Sp3 (Figure 4a) shows the presence of elements, i.e., $\mathrm{C}, \mathrm{O}, \mathrm{N}, \mathrm{Ni}$, and $\mathrm{Co}$ on the surface of the measured sample that is similar to the pristine sample. Furthermore, a tiny amount of potassium ( 0.3 at.\%) was found on the sample as an impurity, probably caused by the adsorption of $\mathrm{K}^{+}$ions from the electrolyte onto the surface of the electrode. On the other hand, high resolution spectra of $\mathrm{Ni} 2 \mathrm{p}, \mathrm{Co} 2 \mathrm{p}$, and $\mathrm{O} 1 \mathrm{~s}$ of $\mathrm{NiCo}-\mathrm{Sp} 3$ reveal a tremendous change in their oxidation stage after stability tests. As shown in Figure $4 \mathrm{~b}$, the two peaks characterized as oxide and metal phase of nickel (at 852.8 and $854.1 \mathrm{eV}$, respectively) in the pristine catalyst (NiCo-Sp0), were depleted from the $\mathrm{Ni} 2 \mathrm{p}_{3 / 2}$ spectrum of $\mathrm{NiCo}-\mathrm{Sp} 3$ which now shows only one peak at the binding energy of $856 \mathrm{eV}$ which can be assigned to $\mathrm{Ni}(\mathrm{OH})_{2}$ [46]. This proves that nickel and nickel oxide reacted further with hydroxyl ions to form a layer of nickel hydroxide on the catalyst surface during the OER in $\mathrm{KOH}$ electrolyte, as expected [50]. Similarly, the transformation of cobalt oxide to cobalt hydroxide during the OER was also noted, where the main peak of $\mathrm{Co} 2 \mathrm{p}_{3 / 2}$ spectrum of $\mathrm{NiCo}-\mathrm{Sp} 3$ (Figure $4 \mathrm{c}$ ) was shifted to a higher binding energy level $\left(780.8 \mathrm{eV}\right.$, assigned as $\left.\mathrm{Co}(\mathrm{OH})_{2}[46]\right)$ than that of the pristine catalyst $(780 \mathrm{eV}$, assigned as cobalt oxides). Furthermore, the $\mathrm{O}$ 1s high-resolution spectrum (Figure 4d) shows a dominant peak at $531.6 \mathrm{eV}$ assigned as the metal-bound hydroxide group $(\mathrm{M}-\mathrm{OH})$ which is much bigger than the peak of metal-bound oxygen $(\mathrm{M}=\mathrm{O})$. The results obtained from XPS confirm that during the OER the developed NiCo catalyst is converted to the corresponding hydroxide form, resulting in a much better performance toward OER than the pristine catalyst.

\subsection{The MOR Performance}

The electrocatalytic activity of the as-prepared NiCo@CNTs/CF electrode toward the methanol oxidation reaction (MOR) was investigated by CV scans which were performed before and after adding methanol $(0.5 \mathrm{M})$ to the $1 \mathrm{M} \mathrm{KOH}$ electrolyte solution. As shown in Figure 5a, in the absence of methanol, the NiCo@CNTs/CF electrode exhibits very low anodic current at the potential range from 0 to $\sim 0.5 \mathrm{~V}$ vs. $\mathrm{Ag} / \mathrm{AgCl}$ owing to the high onset potential toward OER (around $0.55 \mathrm{~V}$ vs. $\mathrm{Ag} / \mathrm{AgCl}$ ) of the pristine electrode. After the addition of methanol, at the same investigated potential range, a much higher anodic current was observed which is, obviously, due to the oxidation of methanol at the electrode. Moreover, based on the CVs, the onset potential of our NiCo@CNTs/CF electrode was estimated to be only around $0.3 \mathrm{~V}$ vs. $\mathrm{Ag} / \mathrm{AgCl}$ (Figure S8) which is similar to the previously reported results of $\mathrm{NiCo}_{2} \mathrm{O}_{4}$ catalyst for MOR [51,52]. 

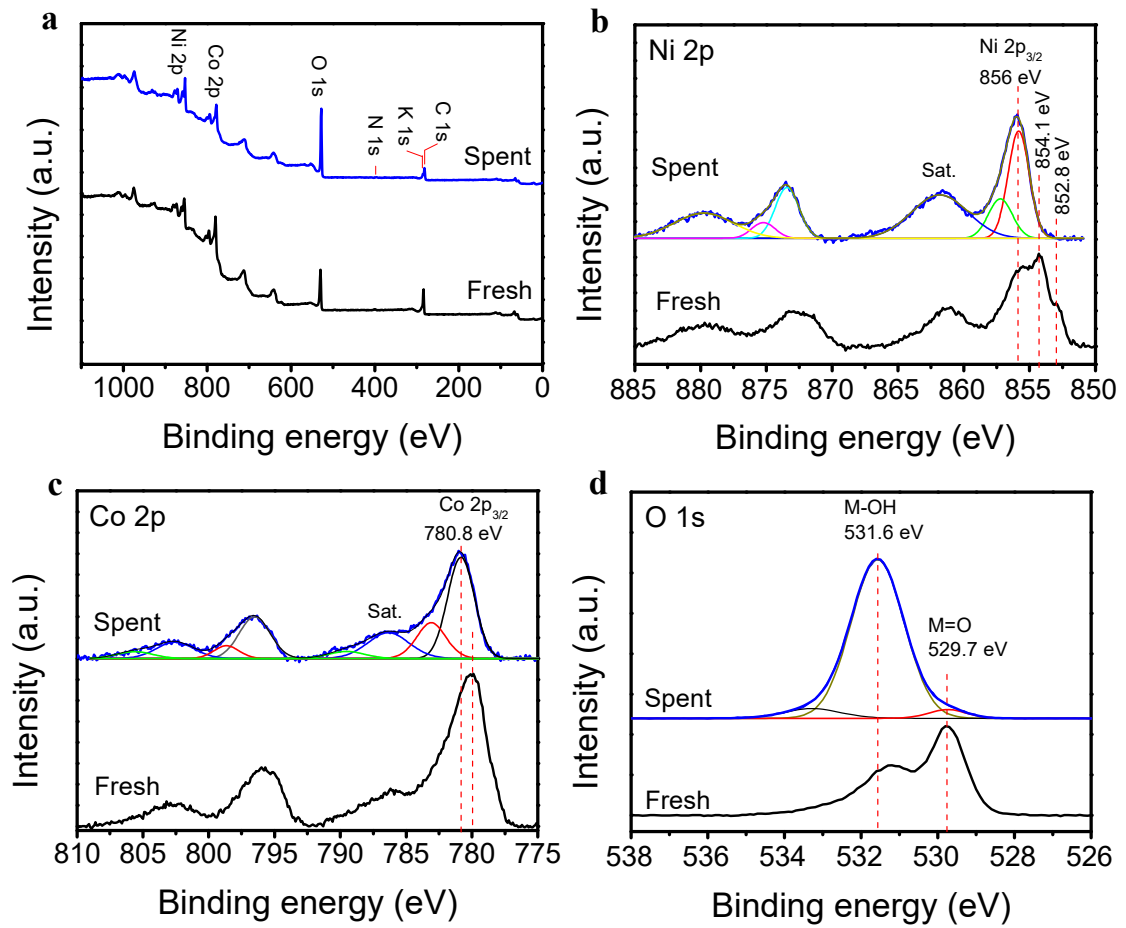

Figure 4. (a) The XPS wide spectra and the high resolution spectra of Ni 2p (b), Co 2p (c), and O 1s (d) of the fresh (NiCo-Sp0) and spent (NiCo-Sp3) of NiCo@CNTs/CF sample.

a

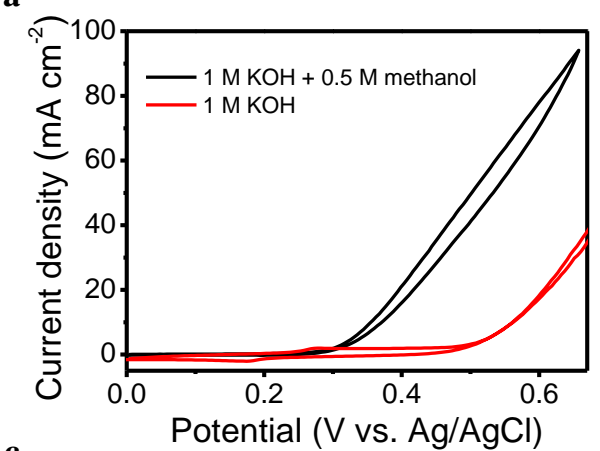

c

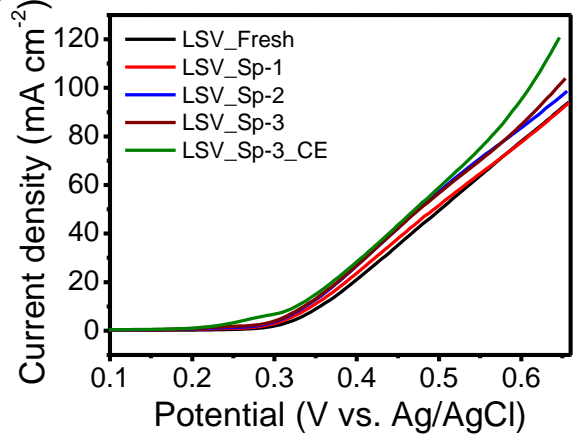

b
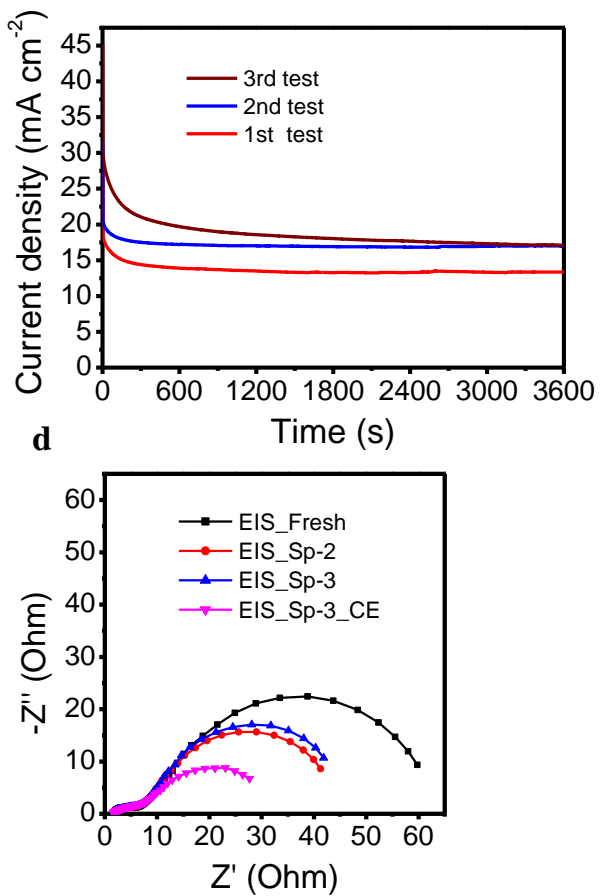

Figure 5. (a) Contrastive CV curves of the NiCo@CNTs/CF electrode in $1 \mathrm{M} \mathrm{KOH}$ and $1 \mathrm{M} \mathrm{KOH}+$ $0.5 \mathrm{M} \mathrm{CH}_{3} \mathrm{OH}$, (b) Potentiostatic curves at a constant potential of $0.4 \mathrm{~V}$ vs. Ag/ $\mathrm{AgCl}$, (c) LSV curves and (d) Nyquits plots at $0.3 \mathrm{~V}$ vs. $\mathrm{Ag} / \mathrm{AgCl}$ of the electrode before and after potentiostatic tests.

To investigate the performance toward the MOR of the NiCo@CNTs/CF electrode, 3 consecutive potentiostatic tests were carried out at a constant potential of $0.4 \mathrm{~V}$ vs. $\mathrm{Ag} / \mathrm{AgCl}$ in $1 \mathrm{M} \mathrm{KOH}$ plus $0.5 \mathrm{M}$ methanol electrolyte solution. Furthermore, after each 
potentiostatic test, LSV and EIS techniques were used to evaluate the electrocatalytic activity of the electrode. As shown in Figure 5b, in the 1st cycle, after an apparent decrease in the current density at the beginning, the electrode shows good stability where no obvious decay in the current density was observed in $1 \mathrm{~h}$. The 2 nd potentiostatic test shows the same trend but with a much better MOR performance with an increase of nearly $30 \%$ in the recorded current density. The result also implies that the observed depletion of the current density at the beginning of potentiostatic tests wasn't caused by the poisoning of the oxidation intermediate, as reported in many studies [51,53,54], but could be assigned to the mass transfer issue where the rate of diffusion of methanol from the bulk to the carbon foam electrode is slower than the consumption rate. The third test, however, exhibits a different pattern in which a more gradual decrease in the current density was observed. Despite the downward trend, a similar current density $\left(\sim 17 \mathrm{~mA} \mathrm{~cm}^{-2}\right)$ as the previous potentiostatic test, was achieved at the end of the third test. To explain these findings, further investigations on the electrocatalytic activity of the NiCo@CNTs/CF electrode were performed.

To further study the electrocatalytic activity expressed as the recorded potential at the current density of $10 \mathrm{~mA} \mathrm{~cm} \mathrm{~cm}^{-2}$ of the NiCo@CNTs/CF electrode, after each potentiostatic cycle, linear sweep voltammetric (LSV) scans, hereafter referred as 'LSV_Sp-x' (where $\mathrm{x}$ is the order number of the potentiostatic test), were immediately conducted without any change in the electrolyte. As shown in Figure 5c, the LSV results reveal an improved performance of the electrode for MOR. The tendency can be seen through a decline in the recorded potentials at the current density of $10 \mathrm{~mA} \mathrm{~cm}^{-2}$ which dropped from $\sim 0.356 \mathrm{~V}$ (the fresh electrode, LSV_Fresh) down to $0.335 \mathrm{~V}$ vs. Ag/ AgCl after the 2nd potentiostatic test (LSV_Sp-2). The voltammetric response performed after the third potentiostatic test (LSV_Sp-3), showed a similar electrocatalytic activity with that of the LSV_Sp-2 which is very consistent with the results observed from the potentiostatic curves. Interestingly, after replacing the old electrolyte with a new electrolyte solution, the recorded LSV (LSV_Sp3_CE) exhibits a slightly better electrocatalytic activity than that of the LSV_Sp-2 and also LSV_Sp-3, especially in the high potential region. At the scan rate of $10 \mathrm{mV} \mathrm{s}^{-1}$, a high current density of $100 \mathrm{~mA} \mathrm{~cm}{ }^{-2}$ was obtained at $0.6 \mathrm{~V}$ vs. $\mathrm{Ag} / \mathrm{AgCl}$ (Figure S9) which is on par with other reported 'state-of-the-art' non-precious catalysts for direct electro-oxidation of methanol (Table S2). The onset potential of the electrode estimated, from the LSV_Sp-3_CE curve, is only $\sim 0.26 \mathrm{~V}$ vs. Ag/ $\mathrm{AgCl}$ (Figure S8) which is smaller than that of the pristine electrode $(\sim 0.3 \mathrm{~V})$. Evidently, after the third potentiostatic cycle, the NiCo@CNTs/CF electrode has better electrocatalytic activity than previously. As demonstrated by the LSV results, the trend observed for MOR is similar to that obtained for OER in which $\mathrm{Ni}$ and $\mathrm{Co}$ in alkaline electrolyte react with hydroxyl ions to form hydroxides (Reaction 1 and 2). The oxidation reaction of methanol is enhanced in the presence of metal hydroxides (Reaction 3 and 4, as described below) [50,55-57].

$$
\begin{gathered}
\mathrm{M}+2 \mathrm{OH}^{-} \rightarrow \mathrm{M}(\mathrm{OH})_{2}+2 \mathrm{e}^{-}(\mathrm{M}=\mathrm{Ni}, \mathrm{Co}) \\
\mathrm{MO}+\mathrm{OH}^{-} \rightarrow \mathrm{MOOH}+\mathrm{e}^{-} \\
\mathrm{M}(\mathrm{OH})_{2} \rightarrow \mathrm{MOOH}+\mathrm{H}^{+}+\mathrm{e}^{-} \\
4 \mathrm{MOOH}+4 \mathrm{CH}_{3} \mathrm{OH}+5 \mathrm{O}_{2} \rightarrow 4 \mathrm{M}(\mathrm{OH})_{2}+4 \mathrm{CO}_{2}+6 \mathrm{H}_{2} \mathrm{O}
\end{gathered}
$$

To confirm the improvement of the performance toward MOR of the NiCo@CNTs/CF electrode, EIS experiments were conducted before (EIS_Fresh) and after each potentiostatic test, hereafter referred as 'EIS_Sp-x' (where $\mathrm{x}$ is the order number of the potentiostatic test) at the potential of $0.3 \mathrm{~V}$ vs. $\mathrm{Ag} / \mathrm{AgCl}$. To eliminate the influence of OER on the EIS results, the potential was selected within the MOR active region but still lower than the OER onset potential of the electrode. The resulting Nyquist plots (Figure 5d) and the corresponding Bode-phase plots (Figure S10) display a similar pattern as observed in OER. Thus, the same model (Figure S4) was used to calculate the charge transfer resistance $\left(R_{c t}\right)$ value of 
EIS spectra. The results show that the calculated $R_{\text {ct }}$ value of the EIS_Sp-3_CE spectrum is $18.3 \Omega$ which is much smaller than the $R_{\text {ct }}$ value of other EIS spectra, e.g., EIS_Sp-3, EIS_Sp-2, and EIS_Fresh (39.0, 36.8, and $57.2 \Omega$, respectively). The EIS results confirm the increased MOR performance, i.e., faster electron transfer and more favorable MOR kinetics of the NiCo@CNTs/CF electrode during the anodic processes. The declining trend observed during the third potentiostatic test could be due to the depletion of methanol with time. Overall, the results obtained from potentiostatic, LSVs, and EIS tests approve the excellent MOR performance of the electrode.

\section{Materials and Methods}

\subsection{Materials}

Melamine foam (Basotect $\mathrm{G}$ ) was purchased from BASF (Ludwigshafen, Germany). Cobalt (II) acetate tetrahydrate $\left(\mathrm{Co}\left(\mathrm{C}_{2} \mathrm{H}_{3} \mathrm{O}_{2}\right)_{2} \cdot 4 \mathrm{H}_{2} \mathrm{O}\right)$, nickel (II) nitrate hexahydrate $\left(\mathrm{Ni}\left(\mathrm{NO}_{3}\right)_{2} \cdot 6 \mathrm{H}_{2} \mathrm{O}\right)$, cobalt (II) nitrate hexahydrate $\left(\mathrm{Co}\left(\mathrm{NO}_{3}\right)_{2} \cdot 6 \mathrm{H}_{2} \mathrm{O}\right)$, and thiophene $\left(\mathrm{C}_{4} \mathrm{H}_{4} \mathrm{~S}\right.$, 99\%) were purchased from Sigma Aldrich (St. Louis, MO, USA). Dimethylformamide (DMF) was purchased from VWR (Radnor, PA, USA). Carbon glue was purchased from PELCO (Fresno, CA, USA). All chemicals were used as received.

\subsection{Synthesis of Carbon Foam}

The carbon foam sample (CF) was synthesized following the procedure described in our previous work [16]. Briefly, the precursor, melamine-based polymer foam (BASF, Basotect $\mathrm{G}$, used as received), was pyrolyzed at $900{ }^{\circ} \mathrm{C}\left(6 \mathrm{~h}\right.$, the ramping rate of $\left.5^{\circ} \mathrm{C} / \mathrm{min}\right)$ in a quartz reactor under $\mathrm{N}_{2}$ flow $\left(50 \mathrm{~mL} \mathrm{~min}^{-1}\right)$. After the pyrolysis, the furnace was allowed to cool down to room temperature under a nitrogen atmosphere. Finally, the synthesized $\mathrm{CF}$ was washed several times with water and then dried at $80^{\circ} \mathrm{C}$ in air, overnight.

\subsection{Synthesis of Carbon Nanotubes (CNT) on Carbon Foam}

Overall, $20 \mathrm{mg}$ of cobalt (II) acetate tetrahydrate was dissolved in $5 \mathrm{~mL}$ of dimethylformamide (DMF) and sonicated for $3 \mathrm{~min}$. The carbon foam sample ( 20 mg) was put into the mixture together with $65 \mu \mathrm{L}$ of thiophene. The mixture was dried at $125^{\circ} \mathrm{C}$ under nitrogen flow. To grow CNTs on the carbon foam substrate, the catalytic chemical vapor deposition (CCVD) method was employed. The sample was placed on a quartz boat which then was inserted into a horizontal quartz tube. The system was purged with the Varigon gas $\left(5 \%\right.$ hydrogen in argon gas, $\left.180 \mathrm{~mL} \mathrm{~min}^{-1}\right)$ for $20 \mathrm{~min}$ and then heated to $670{ }^{\circ} \mathrm{C}$ with the ramping rate of $\sim 30^{\circ} \mathrm{C} \mathrm{min}^{-1}$. After that, acetylene was introduced into the system

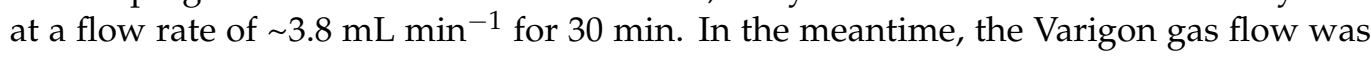
maintained. Finally, the system was allowed to cool down to room temperature under argon gas flow $\left(180 \mathrm{~mL} \mathrm{~min}^{-1}\right)$.

\subsection{Synthesis of Catalyst Material}

NiCo catalyst was deposited on the surface of the carbon foam using the hydrothermal method. In general, $0.04 \mathrm{~g}$ of $\mathrm{Ni}\left(\mathrm{NO}_{3}\right)_{2} \cdot 6 \mathrm{H}_{2} \mathrm{O}, 0.04 \mathrm{~g} \mathrm{Co}\left(\mathrm{NO}_{3}\right)_{2} \cdot 6 \mathrm{H}_{2} \mathrm{O}$, and $0.08 \mathrm{~g}$ urea were dissolved in a $10 \mathrm{~mL}$ mixture of distilled water and ethanol (60:40) with a magnetic stirrer in around $10 \mathrm{~min}$ to form a clear solution. After the addition of the CNTs/CF sample $(\sim 0.01 \mathrm{~g})$, the mixture was transferred to a Teflon-lined autoclave. The autoclave was sealed and then heated at $100{ }^{\circ} \mathrm{C}$ for $8 \mathrm{~h}$. After the reaction, the sample was washed several times with distilled water and ethanol, then dried at $100{ }^{\circ} \mathrm{C}$ in air overnight. Finally, the carbon sample was annealed at $300^{\circ} \mathrm{C}$ for $3 \mathrm{~h}$ in a nitrogen atmosphere $\left(50 \mathrm{~mL} \mathrm{~min}{ }^{-1}\right)$.

\subsection{Characterization Techniques}

Scanning electron microscopy (SEM) and Energy Dispersive X-ray Spectroscopy (EDS) were carried out using a Zeiss Merlin FEG-SEM instrument (Oberkochen, BW, Germany). Thermogravimetric analysis (TGA) was conducted on a Mettler Toledo equipment (TGA/DSC 1LF, Columbus, OH, USA) operated at a heating rate of $10{ }^{\circ} \mathrm{C} \mathrm{min}{ }^{-1}$ 
up to $950{ }^{\circ} \mathrm{C}$ in air. The surface area measurements were carried out by $\mathrm{N}_{2}$ sorption and desorption analysis (Tristar 3000 apparatus, Micrometrics Instrument Corp., Norcross, GA, USA). The surface area of samples was calculated by multipoint nitrogen gas sorptiometry according to the Brunauer-Emmett-Teller principle. Before the analysis, the sample was degassed at $110{ }^{\circ} \mathrm{C}$ in $3 \mathrm{~h}$ in $\mathrm{N}_{2}$ atmosphere. The surface chemistry of the samples was examined using X-ray photoelectron spectroscopy (XPS) method. The photoelectron spectra were collected with a Kratos Axis Ultra DLD electron spectrometer (Kratos Analytical Ltd., Manchester, GMUK) using a monochromated Al K $\alpha$ source operated at $120 \mathrm{~W}$. An analyzer pass energy of $160 \mathrm{eV}$ for acquiring wide spectra and a pass energy of $20 \mathrm{eV}$ for individual photoelectron lines were used. The surface potential was stabilized by the spectrometer charge neutralization system. The binding energy scale was referenced to the $\mathrm{C} 1 \mathrm{~s}$ line of aliphatic carbon, set at $285.0 \mathrm{eV}$ and the processing of the spectra was accomplished with Vision 2 software provided by Kratos Analytical Ltd. The concentrations of nickel and iron elements in the electrolyte and the digested solution, respectively, were determined using Inductively Coupled Plasma-Optical Emission Spectrometer (ICP-OES) Optima 2000 DV (Perkin Elmer Instruments, Kwun Tong, Kowloon, Hong Kong, China). The X-ray diffraction (XRD) patterns were recorded in the $2 \theta$ angle range of $10-70^{\circ}$ with a scan rate of $1^{\circ} \mathrm{min}^{-1}$ on a Panalytical $X^{\prime}$ Pert3 powder diffractometer (Malvern Panalytical, Malvern, Worcs, $\mathrm{UK})$ using $\mathrm{Cu} \mathrm{K} \alpha$ radiation.

\subsection{Electrochemical Measurements}

To prepare the electrodes, the carbon foam samples (with and without catalyst) were attached to a copper foil using the carbon glue (Figure S11). To eliminate the effect of copper on the electrochemical measurements, carbon glue was used to completely cover the copper foil, as well as the copper wire. All electrochemical measurements were performed with a Modulab electrochemical system, ECS (Solartron Analytical, Hampshire, UK). For the 3-electrodes setup measurements in this study, the prepared carbon foam electrodes, a platinum coil, and an $\mathrm{Ag} / \mathrm{AgCl}(1 \mathrm{M} \mathrm{KCl})$ were used as the working, counter, and reference electrodes, respectively. The $1 \mathrm{M} \mathrm{KOH}$ solution was used as the electrolyte which was later employed as-prepared in OER experiments. Cyclic voltammetry (CV) experiments were often performed at a scan rate of $5 \mathrm{mV} \mathrm{s}^{-1}$ unless otherwise noted. All of the LSV and CVs (for OER and MOR) were recorded after some preliminary measurements except the first LSV-OER measurement (NiCo-SP0) in which the first LSV was recorded and used for comparison purposes. The anodization process was performed at a current density of $10 \mathrm{~mA} \mathrm{~cm}^{-2}$ for $10 \mathrm{~h}$ in $1 \mathrm{M} \mathrm{KOH}$ electrolyte which can also be considered as a galvanostatic test. Electrochemical impedance spectroscopy (EIS) experiments were performed at defined potentials, i.e., at the overpotential of $0.3 \mathrm{~V}$ for OER and $0.3 \mathrm{~V}$ vs. $\mathrm{Ag} / \mathrm{AgCl}$ for $\mathrm{MOR}$ in the frequency range 105 to $0.1 \mathrm{~Hz}$ at 10 data points/decade with an applied alternating voltage of $10 \mathrm{mV}$. All measured potentials in OER were calibrated to RHE using the Nernst equation: $\mathrm{E}_{\mathrm{RHE}}=\mathrm{E}_{\mathrm{Ag} / \mathrm{AgCl}}+0.235+0.059 \mathrm{pH}$. The $\mathrm{iR}$-corrected potential was obtained using the equation $\mathrm{E}_{\mathrm{iR}}$ corrected $=\mathrm{E}-(95 \% \mathrm{iR})$, where i represents the current, and $\mathrm{R}$ represents the ohmic resistance of the electrolyte, which was determined using EIS. The Tafel plots were derived from the polarization curves. The linear regions of the Tafel plots are fitted to the Tafel equation $\eta=b \log j+a$ where $\eta$ is overpotential, $j$ is the current density, and $b$ is the Tafel slope, respectively. To evaluate the double layer capacitance values, $C_{\mathrm{dl}}$, CVs were collected at different scan rates $(v)\left(1,5,10,20,40 \mathrm{mV} \mathrm{s}^{-1}\right)$ in a non-Faradaic current region. The $C_{d l}$ was determined from the equation: $i_{c}=v C_{d l}$ by plotting $i_{c}$ versus $v$ where $i_{c}$ is the capacitive current.

\subsection{Leaching Test of Catalysts in the Electrolyte}

In general, the stability tests (galvanostatic measurements) were performed in a single electrochemical cell that contains $7 \mathrm{~mL}$ of $1 \mathrm{M} \mathrm{KOH}$ electrolyte. After the stability tests, the concentration of catalyst in the electrolyte sample was measured by ICP-OES. Certified 
stock solutions of nickel and cobalt $\left(1000 \mu \mathrm{g} \mathrm{mL}^{-1}\right)$ were used for the preparation of the standard solutions used for the construction of calibration curves.

\subsection{Determination of the Catalyst Loading of NiCo on CF-CNT Using ICP-OES}

In a typical process, the sample was ground into a powder form and digested with concentrated nitric acid (60\%). The mixture was sonicated in ca. $20 \mathrm{~min}$ and digested at $125{ }^{\circ} \mathrm{C}$ overnight (reflux). The final clear solution was then diluted with an appropriate amount of Milli- $\mathrm{Q}^{\circledR}$ water for the determination of nickel and cobalt using ICP-OES.

\section{Conclusions}

In summary, a 3D structured NiCo@CNTs/CF was successfully synthesized in which nanoneedles of NiCo catalyst were decorated on the surface of the CNTs/carbon foam. The morphology and the physio-chemical properties of the synthesized electrode/catalyst were carefully studied by various techniques: SEM, TGA, ICP-OES, XRD, and XPS. The electrochemical activity of the developed electrode towards the oxygen evolution reaction and also methanol oxidation was thoroughly investigated. The achieved results have proven that the NiCo@CNTs/CF electrode can be used as a bi-functional catalyst for OER and MOR as it shows high electrocatalytic activity and excellent durability in both reactions. The excellent performance of NiCo@CNTs/CF is attributed to its components, i.e., the bi-functionality of the NiCo catalyst, carbon nanotubes, and 3D structured carbon foam which provide many unique properties, e.g., excellent electrocatalytic activity for both OER and MOR, high surface area, oxidation resistance, as well as the rapid and unhindered diffusion of reactants and products in the bulk and the whole electrode matrix. Our study shows that the bi-functional NiCo@CNTs/CF electrode has the potential to be applied as an efficient, cheap, and eco-friendly anode for water electrolysis and DMFCs.

Supplementary Materials: The following are available online at https:/ / www.mdpi.com/article/10 .3390 / catal11040500/s1, Figure S1: The nitrogen adsorption-desorption isotherm curves of CNTs/CF and NiCo@CNTs/CF samples, Figure S2: Thermogravimetric analysis results of the blank (CNTs/CF) and the NiCo@CNTs/CF sample, Figure S3: XPS wide spectra of the fresh NiCo@CNTs/CF samples, Figure S4: Equivalent circuit model used in the Nyquist plots, Figure S5: The CVs curves of the NiCo@CNTs/CF electrode before (a) and after $(\mathbf{b})$ the anodization. The calculated $\mathrm{C}_{\mathrm{dl}}$ of the electrode before (c) and after (d) the anodization, Figure S6: SEM images of the spent (after the third galvanostatic test) NiCo@CNTs/CF sample at low (left) and high (right) magnification, Figure S7: SEM-EDX mapping of $\mathrm{C}, \mathrm{Ni}$, and Co elements on the NiCo@CNTs/CF sample after the third galvanostatic test, Figure S8: Determination of the onset potential before and after each potentiostatic test of the NiCo@CNTs/CF electrode (LSV_Sp-3_CE: The LSV was performed after the third potentiostatic test and then change the old electrolyte by the new electrolyte), Figure S9: The CV curve of the NiCo@CNTs/CF electrode after the third potentiostatic test and change the electrolyte $(1 \mathrm{M} \mathrm{KOH}$ $+0.5 \mathrm{M} \mathrm{CH}_{3} \mathrm{OH}$ ) at a scan rate of $10 \mathrm{mV} \mathrm{s}^{-1}$, Figure S10: Bode-phase plots of the NiCo@CNTs/CF electrode at the potential of $0.3 \mathrm{~V}$ vs. $\mathrm{Ag} / \mathrm{AgCl}$, Figure S11: Picture of a carbon foam electrode before being covered by the carbon glue, Table S1: Comparison of the OER performance of reported NiCo based electrocatalysts at the current density $\eta=10 \mathrm{~mA} \mathrm{~cm}^{-2}$ in $1 \mathrm{M} \mathrm{KOH}$ electrolyte, Table S2: Comparison of the MOR performance of reported NiCo based electrocatalysts in $1 \mathrm{M} \mathrm{KOH}+0.5 \mathrm{M}$ $\mathrm{CH}_{3} \mathrm{OH}$ electrolyte.

Author Contributions: Conceptualization, T.N.P.; methodology, T.N.P.; formal analysis, T.N.P. and A.S.; resources, J.-P.M., T.W., and S.T.; writing-original draft preparation, T.N.P.; writing-review and editing, S.T., A.S., T.W., and J.-P.M.; supervision, J.-P.M.; All authors have read and agreed to the published version of the manuscript.

Funding: The Kempe Foundations are acknowledged for funding. T.W. acknowledges support from Energimyndigheten (45419-1). This work is also supported by the University of Danang, project's code number: B2018-ĐN02-48. This research is also a part of the activities of the Bio4Energy programme in Sweden and the Åbo Akademi Process Chemistry Centre in Finland.

Data Availability Statement: Data are contained within the article and Supplementary Material. 
Acknowledgments: Umeå Core Facility Electron Microscopy (UCEM) are acknowledged for their technical assistance in capturing the SEM images. The authors also thank Andrey Shchukarev for his technical assistance in capturing and deconvoluting the XPS spectra.

Conflicts of Interest: The authors declare no conflict of interest.

\section{References}

1. Ibrahim, H.; Ilinca, A.; Perron, J. Energy storage systems-Characteristics and comparisons. Renew. Sustain. Energy Rev. 2008, 12, 1221-1250. [CrossRef]

2. Walter, M.G.; Warren, E.L.; McKone, J.R.; Boettcher, S.W.; Mi, Q.; Santori, E.A.; Lewis, N.S. Solar water splitting cells. Chem. Rev. 2010, 110, 6446-6473. [CrossRef]

3. Smith, R.D.; Prévot, M.S.; Fagan, R.D.; Zhang, Z.; Sedach, P.A.; Siu, M.K.J.; Trudel, S.; Berlinguette, C.P. Photochemical route for accessing amorphous metal oxide materials for water oxidation catalysis. Science 2013, 340, 60-63. [CrossRef] [PubMed]

4. Lee, Y.; Suntivich, J.; May, K.J.; Perry, E.E.; Shao-Horn, Y. Synthesis and activities of rutile $\mathrm{IrO}_{2}$ and $\mathrm{RuO}_{2}$ nanoparticles for oxygen evolution in acid and alkaline solutions. J. Phys. Chem. Lett. 2012, 3, 399-404. [CrossRef] [PubMed]

5. Jiang, B.; Li, C.; Malgras, V.; Imura, M.; Tominaka, S.; Yamauchi, Y. Mesoporous Pt nanospheres with designed pore surface as highly active electrocatalyst. Chem. Sci. 2016, 7, 1575-1581. [CrossRef]

6. Mayavan, S.; Jang, H.-S.; Lee, M.-J.; Choi, S.H.; Choi, S.-M. Enhancing the catalytic activity of Pt nanoparticles using poly sodium styrene sulfonate stabilized graphene supports for methanol oxidation. J. Mater. Chem. A 2013, 1, 3489-3494. [CrossRef]

7. Kua, J.; Goddard, W.A. Oxidation of methanol on 2nd and 3rd row group VIII transition metals (Pt, Ir, Os, Pd, Rh, and $\mathrm{Ru}$ ): Application to direct methanol fuel cells. J. Am. Chem. Soc. 1999, 121, 10928-10941. [CrossRef]

8. Sharifi, T.; Gracia-Espino, E.; Jia, X.; Sandström, R.; Wågberg, T. Comprehensive Study of an Earth-Abundant Bifunctional 3D Electrode for Efficient Water Electrolysis in Alkaline Medium. ACS Appl. Mater. Interfaces 2015, 7, 28148-28155. [CrossRef]

9. Lu, X.; Zhao, C. Electrodeposition of hierarchically structured three-dimensional nickel-iron electrodes for efficient oxygen evolution at high current densities. Nat. Commun. 2015, 6. [CrossRef]

10. Du, P.; Eisenberg, R. Catalysts made of earth-abundant elements (Co, Ni, Fe) for water splitting: Recent progress and future challenges. Energy Environ. Sci. 2012, 5, 6012-6021. [CrossRef]

11. Jadhav, A.R.; Bandal, H.A.; Chaugule, A.A.; Kim, H. Diethylenetriamine assisted synthesis of mesoporous Co and Ni-Co spinel oxides as an electrocatalysts for methanol and water oxidation. Electrochim. Acta 2017, 240, 277-287. [CrossRef]

12. Liu, Y.; Hu, B.; Wu, S.; Wang, M.; Zhang, Z.; Cui, B.; He, L.; Du, M. Hierarchical nanocomposite electrocatalyst of bimetallic zeolitic imidazolate framework and $\mathrm{MoS}_{2}$ sheets for non-Pt methanol oxidation and water splitting. Appl. Catal. B Environ. 2019, 258, 117970. [CrossRef]

13. Gong, M.; Li, Y.; Wang, H.; Liang, Y.; Wu, J.Z.; Zhou, J.; Wang, J.; Regier, T.; Wei, F.; Dai, H. An advanced Ni-Fe layered double hydroxide electrocatalyst for water oxidation. J. Am. Chem. Soc. 2013, 135, 8452-8455. [CrossRef]

14. Wang, Z.; Zeng, S.; Liu, W.; Wang, X.; Li, Q.; Zhao, Z.; Geng, F. Coupling molecularly ultrathin sheets of NiFe-layered double hydroxide on $\mathrm{NiCO}_{2} \mathrm{O}_{4}$ nanowire arrays for highly efficient overall water-splitting activity. ACS Appl. Mater. Interfaces 2017, 9 , 1488-1495. [CrossRef] [PubMed]

15. Kuang, M.; Wang, Q.; Ge, H.; Han, P.; Gu, Z.; Al-Enizi, A.M.; Zheng, G. CuCoO $/$ FeOOH Core-shell nanowires as an efficient bifunctional oxygen evolution and reduction catalyst. ACS Energy Lett. 2017, 2, 2498-2505. [CrossRef]

16. Pham, T.N.; Sharifi, T.; Sandström, R.; Siljebo, W.; Shchukarev, A.; Kordas, K.; Wågberg, T.; Mikkola, J.-P. Robust hierarchical 3D carbon foam electrode for efficient water electrolysis. Sci. Rep. 2017, 7, 1-9. [CrossRef]

17. Suntivich, J.; May, K.J.; Gasteiger, H.A.; Goodenough, J.B.; Shao-Horn, Y. A perovskite oxide optimized for oxygen evolution catalysis from molecular orbital principles. Science 2011, 334, 1383-1385. [CrossRef] [PubMed]

18. Cabán-Acevedo, M.; Stone, M.L.; Schmidt, J.; Thomas, J.G.; Ding, Q.; Chang, H.-C.; Tsai, M.-L.; He, J.-H.; Jin, S. Efficient hydrogen evolution catalysis using ternary pyrite-type cobalt phosphosulphide. Nat. Mater. 2015, 14, 1245-1251. [CrossRef]

19. Jiang, N.; Bogoev, L.; Popova, M.; Gul, S.; Yano, J.; Sun, Y. Electrodeposited nickel-sulfide films as competent hydrogen evolution catalysts in neutral water. J. Mater. Chem. A 2014, 2, 19407-19414. [CrossRef]

20. Czioska, S.; Wang, J.; Teng, X.; Chen, Z. Hierarchically structured $\mathrm{CuCo}_{2} \mathrm{~S}_{4}$ nanowire arrays as efficient bifunctional electrocatalyst for overall water splitting. ACS Sustain. Chem. Eng. 2018, 6, 11877-11883. [CrossRef]

21. Tang, C.; Cheng, N.; Pu, Z.; Xing, W.; Sun, X. NiSe nanowire film supported on nickel foam: An efficient and stable 3D bifunctional electrode for full water splitting. Angew. Chem. 2015, 127, 9483-9487. [CrossRef]

22. Gu, Y.; Chen, S.; Ren, J.; Jia, Y.A.; Chen, C.; Komarneni, S.; Yang, D.; Yao, X. Electronic structure tuning in Ni 3 FeN/r-GO aerogel toward bifunctional electrocatalyst for overall water splitting. ACS Nano 2018, 12, 245-253. [CrossRef]

23. Xue, Z.H.; Su, H.; Yu, Q.Y.; Zhang, B.; Wang, H.H.; Li, X.H.; Chen, J.S. Janus Co/CoP nanoparticles as efficient Mott-Schottky electrocatalysts for overall water splitting in wide $\mathrm{pH}$ range. Adv. Energy Mater. 2017, 7, 1602355. [CrossRef]

24. Xiao, P.; Sk, M.A.; Thia, L.; Ge, X.; Lim, R.J.; Wang, J.-Y.; Lim, K.H.; Wang, X. Molybdenum phosphide as an efficient electrocatalyst for the hydrogen evolution reaction. Energy Environ. Sci. 2014, 7, 2624-2629. [CrossRef]

25. Laursen, A.; Patraju, K.; Whitaker, M.; Retuerto, M.; Sarkar, T.; Yao, N.; Ramanujachary, K.; Greenblatt, M.; Dismukes, G.C. Nanocrystalline $\mathrm{Ni}_{5} \mathrm{P}_{4}$ : A hydrogen evolution electrocatalyst of exceptional efficiency in both alkaline and acidic media. Energy Environ. Sci. 2015, 8, 1027-1034. [CrossRef] 
26. Peng, Z.; Jia, D.; Al-Enizi, A.M.; Elzatahry, A.A.; Zheng, G. From water oxidation to reduction: Homologous Ni-Co based nanowires as complementary water splitting electrocatalysts. Adv. Energy Mater. 2015, 5, 1402031. [CrossRef]

27. Li, M.; Tao, L.; Xiao, X.; Jiang, X.; Wang, M.; Shen, Y. Hybridizing $\mathrm{NiCo}_{2} \mathrm{O}_{4}$ and Amorphous $\mathrm{Ni}_{\mathrm{x}} \mathrm{Co}_{\mathrm{y}}$ Layered Double Hydroxides with Remarkably Improved Activity toward Efficient Overall Water Splitting. ACS Sustain. Chem. Eng. 2019, 7, 4784-4791. [CrossRef]

28. Fang, L.; Jiang, Z.; Xu, H.; Liu, L.; Gu, X.; Wang, Y. Crystal-plane engineering of $\mathrm{NiCo}_{2} \mathrm{O}_{4}$ electrocatalysts towards efficient overall water splitting. J. Catal. 2018, 357, 238-246. [CrossRef]

29. Zhu, C.; Fu, S.; Du, D.; Lin, Y. Facilely Tuning Porous $\mathrm{NiCo}_{2} \mathrm{O}_{4}$ Nanosheets with Metal Valence-State Alteration and Abundant Oxygen Vacancies as Robust Electrocatalysts Towards Water Splitting. Chem. A Eur. J. 2016, 22, 4000-4007. [CrossRef]

30. Li, Y.; Hasin, P.; Wu, Y. NixCo ${ }_{3}^{-} \mathrm{O}_{4}$ nanowire arrays for electrocatalytic oxygen evolution. Adv. Mater. 2010, $22,1926-1929$. [CrossRef]

31. Patil, K.; Babar, P.; Lee, D.M.; Karade, V.; Jo, E.; Korade, S.; Kim, J.H. Bifunctional catalytic activity of Ni-Co layered double hydroxide for the electro-oxidation of water and methanol. Sustain. Energy Fuels 2020, 4, 5254-5263. [CrossRef]

32. Prathap, M.A.; Srivastava, R. Synthesis of $\mathrm{NiCo}_{2} \mathrm{O}_{4}$ and its application in the electrocatalytic oxidation of methanol. Nano Energy 2013, 2, 1046-1053. [CrossRef]

33. Wang, T.; Wu, H.; Feng, C.; Zhang, L.; Zhang, J. MoP NiCo-LDH on nickel foam as bifunctional electrocatalyst for high efficiency water and urea-water electrolysis. J. Mater. Chem. A 2020, 8, 18106-18116. [CrossRef]

34. Liu, M.; Jiao, Y.; Zhan, S.; Wang, $\mathrm{H}$. $\mathrm{Ni}_{3} \mathrm{~S}_{2}$ nanowires supported on Ni foam as efficient bifunctional electrocatalyst for urea-assisted electrolytic hydrogen production. Catal. Today 2020, 355, 596-601. [CrossRef]

35. Zhao, D.; Dai, M.; Liu, H.; Chen, K.; Zhu, X.; Xue, D.; Wu, X.; Liu, J. Sulfur-Induced Interface Engineering of $\mathrm{Hybrid} \mathrm{NiCo}_{2} \mathrm{O}_{4} @$ $\mathrm{NiMo}_{2} \mathrm{~S}_{4}$ Structure for Overall Water Splitting and Flexible Hybrid Energy Storage. Adv. Mater. Interfaces 2019, 6, 1901308. [CrossRef]

36. Xiao, C.; Li, Y.; Lu, X.; Zhao, C. Bifunctional porous $\mathrm{NiFe} / \mathrm{NiCo}_{2} \mathrm{O}_{4} / \mathrm{Ni}$ foam electrodes with triple hierarchy and double synergies for efficient whole cell water splitting. Adv. Funct. Mater. 2016, 26, 3515-3523. [CrossRef]

37. Park, H.; Park, B.H.; Choi, J.; Kim, S.; Kim, T.; Youn, Y.-S.; Son, N.; Kim, J.H.; Kang, M. Enhanced Electrochemical Properties and OER Performances by $\mathrm{Cu}$ Substitution in $\mathrm{NiCo}_{2} \mathrm{O}_{4}$ Spinel Structure. Nanomaterials 2020, 10, 1727. [CrossRef]

38. Lehmhus, D.; Vesenjak, M.; Schampheleire, S.D.; Fiedler, T. From stochastic foam to designed structure: Balancing cost and performance of cellular metals. Materials 2017, 10, 922. [CrossRef]

39. Ashby, M.F.; Evans, T.; Fleck, N.A.; Hutchinson, J.; Wadley, H.; Gibson, L. Metal Foams: A Design Guide; Elsevier: Amsterdam, The Netherlands, 2000.

40. Liu, Y.; Bai, Y.; Han, Y.; Yu, Z.; Zhang, S.; Wang, G.; Wei, J.; Wu, Q.; Sun, K. Self-supported hierarchical FeCoNi-LTH/NiCo $2 \mathrm{O}_{4} / \mathrm{CC}^{-}$ electrodes with enhanced bifunctional performance for efficient overall water splitting. ACS Appl. Mater. Interfaces 2017, 9, 36917-36926. [CrossRef]

41. Liu, D.; Lu, Q.; Luo, Y.; Sun, X.; Asiri, A.M. $\mathrm{NiCo}_{2} \mathrm{~S}_{4}$ nanowires array as an efficient bifunctional electrocatalyst for full water splitting with superior activity. Nanoscale 2015, 7, 15122-15126. [CrossRef]

42. Wang, J.; Zhong, H.-X.; Wang, Z.-L.; Meng, F.-L.; Zhang, X.-B. Integrated three-dimensional carbon paper/carbon tubes/cobaltsulfide sheets as an efficient electrode for overall water splitting. ACS Nano 2016, 10, 2342-2348. [CrossRef] [PubMed]

43. Suryanto, B.H.; Wang, Y.; Hocking, R.K.; Adamson, W.; Zhao, C. Overall electrochemical splitting of water at the heterogeneous interface of nickel and iron oxide. Nat. Commun. 2019, 10, 1-10. [CrossRef] [PubMed]

44. Pham, T.N.; Samikannu, A.; Kukkola, J.; Rautio, A.-R.; Pitkänen, O.; Dombovari, A.; Lorite, G.S.; Sipola, T.; Toth, G.; Mohl, M.; et al. Industrially benign super-compressible piezoresistive carbon foams with predefined wetting properties: From environmental to electrical applications. Sci. Rep. 2014, 4, 1-8. [CrossRef] [PubMed]

45. Fu, S.; Zhu, C.; Li, H.; Du, D.; Lin, Y. One-step synthesis of cobalt and nitrogen co-doped carbon nanotubes and their catalytic activity for the oxygen reduction reaction. J. Mater. Chem. A 2015, 3, 12718-12722. [CrossRef]

46. McIntyre, N.; Cook, M. X-ray photoelectron studies on some oxides and hydroxides of cobalt, nickel, and copper. Anal. Chem. 1975, 47, 2208-2213. [CrossRef]

47. Tan, B.J.; Klabunde, K.J.; Sherwood, P.M. XPS studies of solvated metal atom dispersed (SMAD) catalysts. Evidence for layered cobalt-manganese particles on alumina and silica. J. Am. Chem. Soc. 1991, 113, 855-861. [CrossRef]

48. Bredar, A.R.; Chown, A.L.; Burton, A.R.; Farnum, B.H. Electrochemical Impedance Spectroscopy of Metal Oxide Electrodes for Energy Applications. ACS Appl. Energy Mater. 2020, 3, 66-98. [CrossRef]

49. Doyle, R.L.; Lyons, M.E. An electrochemical impedance study of the oxygen evolution reaction at hydrous iron oxide in base. Phys. Chem. Chem. Phys. 2013, 15, 5224-5237. [CrossRef]

50. Medway, S.; Lucas, C.; Kowal, A.; Nichols, R.; Johnson, D. In situ studies of the oxidation of nickel electrodes in alkaline solution. J. Electroanal. Chem. 2006, 587, 172-181. [CrossRef]

51. Faid, A.; Ismail, $\mathrm{H}$. Highly active and easily fabricated $\mathrm{NiCO}_{2} \mathrm{O}_{4}$ nanoflowers for enhanced methanol oxidation. ChemistrySelect 2019, 4, 7896-7903. [CrossRef]

52. Chen, G.; Gao, Y.; Zhang, H. Template-free synthesis of 3D hierarchical nanostructured $\mathrm{NiCo}_{2} \mathrm{O}_{4}$ mesoporous ultrathin nanosheet hollow microspheres for excellent methanol electrooxidation and supercapacitors. Rsc Adv. 2016, 6, 30488-30497. [CrossRef] 
53. Qian, L.; Gu, L.; Yang, L.; Yuan, H.; Xiao, D. Direct growth of $\mathrm{NiCo}_{2} \mathrm{O}_{4}$ nanostructures on conductive substrates with enhanced electrocatalytic activity and stability for methanol oxidation. Nanoscale 2013, 5, 7388-7396. [CrossRef] [PubMed]

54. Tong, X.; Qin, Y.; Guo, X.; Moutanabbir, O.; Ao, X.; Pippel, E.; Zhang, L.; Knez, M. Enhanced catalytic activity for methanol electro-oxidation of uniformly dispersed nickel oxide nanoparticles-Carbon nanotube hybrid materials. Small 2012, 8, 3390-3395. [CrossRef] [PubMed]

55. Spinner, N.; Mustain, W.E. Effect of nickel oxide synthesis conditions on its physical properties and electrocatalytic oxidation of methanol. Electrochim. Acta 2011, 56, 5656-5666. [CrossRef]

56. Heli, H.; Yadegari, H. Nanoflakes of the cobaltous oxide, CoO: Synthesis and characterization. Electrochim. Acta 2010, 55, 2139-2148. [CrossRef]

57. Jafarian, M.; Mahjani, M.; Heli, H.; Gobal, F.; Khajehsharifi, H.; Hamedi, M. A study of the electro-catalytic oxidation of methanol on a cobalt hydroxide modified glassy carbon electrode. Electrochim. Acta 2003, 48, 3423-3429. [CrossRef] 